12 th of March I was obliged to make another incision, inside the ankle, for the freer exit of pus in that position. On the 20th I applied a loose bandage, still keeping on with the poulticing; but this I was obliged to leave off on the $23 \mathrm{rd}$, for the lymphatics became affected and the glands of the groin began to swell. I used iodine and tonic treatment, and did not attempt to bandage again until May 1st. I then bad an apparatus swung from the ceiling, so that the patient could raise his body from the bed, and more conveniently assist himself in his various necessities.

On May 21st I had him removed to a large room, and all went on well for a week. Then the most anxious time arrived. I was called on the $27 \mathrm{th}$, early in the morning, and found him shivering all over and his teeth chattering, the surface of his body quite cold and purple, and the pulse almost imperceptible. I immediately gave him a pint of champagne with a little brandy, and repeated this dose three times during the day, and left off the bandaging, applying orly poultices. In the evening he was better and the rigors ceased, but on the following day they again threatened, and I telegraphed to Mr. Gore for a second consultation. The treatment was not altered, and for some days the champagne was continued.

From this time the patient gradually but very slowly recovered, and on the 20th of June he was able to sit up in an arm-chair, which was a very great relief to him, having remained on his back for nearly four months; and on the 14th of July he was removed to his father's residence, about a mile distant, where he daily improved, riding out frequently in a Bath chair.

On the 3rd of September following Mr. H- went to his own home, seven miles distant, with only a small wound, little larger than a shilling, on the inner side of the ankle, the external opening and the artificial one over the tibia having healed about a month previously. For a very long time this wound was a cause of great trouble and anxiety to me. Although my patient was able to get about his farm in a Bath chair or in a dog-cart, and to superintend his various duties, yet there continued a nasty discharge, which evidently resulted from the irritation caused by a piece of necrosed bone. In November a small piece of bone, about the size of a split pea, came away from the internal malleolus, and the wound nearly healed. Two months afterwards another minute sorap of bone threw itself off; and at last, in February, a year after the occurrence of the accident, the wound healed, and the leg became as whole and perfect as it could be under the circumstances. During the winter Mr. $\mathrm{H}-$ suffered much from a severe attack of bronchitis, which confined him to the house and prevented his getting about for some time; however, last summer he walked a great deal and rode on horseback.

The great point for consideration seems to me to be, Would it be advisable under similar conditions to pursue the same course of treatment that I adopted, or to resort to immediate amputation? I must say that I cannot come to a very firm conclusion myself, if I weigh the chances and risks that $I$ have gone through against the speedy recovery from amputation; and though in the present case the result has been a highly satisfactory one, yet if there had been a less healthy subject to deal with, the dangers and complications must have been considerably greater, and I much fear that the termination of the case would have proved fatal to the patient as well as a source of unceasing regret to the medical man. At the present time $\mathrm{Mr}$. $\mathrm{H}$ can walk ten miles with ease, can ride well and hunt, and the most satisfactory part of his case is, that he has partial use of his ankle-jnint and no shortening of the leg.

Wootton Bassett, Wilts.

\section{THE TREATMENT OF SMALLPOX BY VACCINATION.}

BY MATTHEW TAYLOR, M.B.,

IATE ASSISTANT MRDTOAL OFFYCER AT THE HAMPSTEAD HOSPITAL.

So much has been written upon this subject already that little room is left for anyone to make original observations; still, as the subject has been opened up by the recent articles of Dr. Grieve and Mr. Furley, pro and con., and as further discussion and investigation have been invited by $\mathrm{Mr}$.
Furley in his article in The LANCET for August 10th, it may be useful to record what little experience I have had in vaccinating during the progress of variola.

While assistant medical officer at Hampstead Hospital, on the publication of Mr. Furley's letters in the newspapers, Dr. Grieve, Mr. Bland, and myself made a series of experiments, which Dr. Grieve has not referred to in his article in your pages, but with precisely similar results. As far as my memory serves me, we vaccinated four cases, two of which were unvaccinated and two vaccinated. Of the two vaccinated cases both were mild cases and both aborted, but not sooner than in all probability they would have done if left to nature. Of the two unvaccinated cases, one died two days after-I don't mean to insinuate from the vaccine lymph having been used; but certainly it did nothing to modify the virulence of the attack. The other case was most interesting, as in it the vaccinia and variola ran their course side by side, without the one seeming in the slightest degree to affect the other. The child was a little gipsy girl of about eight years of age, and was vaccinated in the vesicular stage of the small-pox immediately on her admission. She had a very severe attack, the disease running a quite unmodified course, though the vaccine vesicles could be distinctly seen on the arm.

Such were the results of the first series of experimentscertainly not such as to encourage us in its continuance; yet, notwithstanding, I was much pleased to see that another series of experiments had been instituted, though evidently with no better result. Nevertheless, I find that Mr. Furley still maintains his ground and contends that vaccination, during the course of the disease, has a curative effect. It seems to me that $\mathbf{M r}$. Furley makes a grand mistake in the very outset, as by his own analysis of his cases the great majority on which he experimented were vaccinated cases. Now, anyone at all conversant with small-pox knows that in perhaps 95 per cent. of vaccinated cases the disease does not run its natural course, but is modified and may abort at any stage; consequently, in experimenting upon vaccinated cases, one is not experimenting on small-pox, but on a modified disease-modifed to a greater or less extent according to the number and nature of the vaccine cicatrices, and the re:ults, in a statistical point of view, are quite worthless. Who can say that the disease would not have aborted earlier in these vaccinated cases if left alone? Cases of small-pox, pure and simple, unmodified and unvaccinated, are the oaly proper cases for experiment, and the only ones which give reliable data. Now, striking out all vaccinated cases, and referring only to Mr. Furley's unvaccinated cases, I would ask-Is his percentage of deaths in these cases larger or' srualler than the average of such cases in the London small-pox hospitals during the epidemic? If there is a marked difference in the percentage of deaths, then I will believe there is something in the vaccination theory. If one thing more than another was impressed upon me during my residence in Hampstead Hospital it was the value of vaccination and revaccination as preventives to small-pox, but not as curative agents. Mr. Furley seems to scout the opinion of Mr. Marson and others, that a person may be vaccinated-say on Thursday-and yet, if delayed twelve hours, it would be too late. I have seldom, in my experience of small-pox (which extends to some 1200 cases), found Mr. Marson very far wrong in his deductions. He has seen too many cases, and is too accurate an observer for that; and I have seen sufficient to justify me in supporting the opinion of Mr. Marson, Dr. Grieve, and others, that vaccination may be of use today, too late to-morrow; and I dare say most medical men will be ready to corroborate that opinion. If the effect of introducing vaccine lymph were instantaneous, then $\mathrm{Mr}$. Furley might be right. But anyone who has given the subject careful consideration knows that the preventive action of the vaccine virus does not come into operation till the constitutional effect is produced, or, in otber words, till the maturation of the vesicle, which occurs in nine days. Now it has been demonstrated clearly that the period of incubation in small-pox, from the time of exposure to the virus till the appearance of the eruption, is, as nearly as possible, fourteen days. The opinion beld by Mr. Marson, Dr. Grieve, and others, and in which, from my own experience, $I$ concur, is that if a person be vaccinated so that the vesicles arrive at maturation before the small pox eruption appears, he is safe; if the small-pox eruption 
appears first, the chances are that it will run its course unmodified by the vaccinia. Suppose A. B., an unvaccinated person, is exposed to the variolous virus on Monday, the rash will, in all probability, appear on the following Sunday week. If he is vaccinated on the Tuesday, he is safe; or the Wednesday, Thursday, or even up to the Friday; but if delayed till the following Monday, it is quite useless, and might as well not be done; for, in nine cases out of ten, the disease will run its course unaffected by the vaccination. If the opinion I have expressed be correct-viz., that vaccination is of no use until the maturation of the vesiclethen why vaccinate during the appearance of small-tox eruption? Before the nine days necessary for its maturation have elapsed the disease will either have passed the crisis or have terminated fatally.

As to the theories Mr. Furley has put forward respecting the "pabulum" and the blood, I say nothing further than that it fails to account for many of the phenomena observable in small-pox. However, it is a wide field for speculation, and some further light may be educed from those who have made the action of specific poisons on the system a special study. The conclusion to which I come, from the experiments I have mentioned, confirmed by the further experiments of Dr. Grieve, is, that revaccination or vaccination after the appearance of the rash is powerless to check the disease, if not injurious; but let me add my humble testimony to the value of vaccination and revaccination as preventives.

Grenada, West Indies, 10th Sept. 1872.

\section{NEW INSUFFLATOR FOR TREATING DIS- EASES OF THE UTERUS, ETC.}

\section{BY JOHN CLAY,}

OBSTETRIC SURGRON TO THE QUEBN'S HOSPITAL, BIRMINGHAM.

Having used the insufflator (see THE LANCET, Nov. 30th, 1872) in a number of cases of diseases of the uterus, and

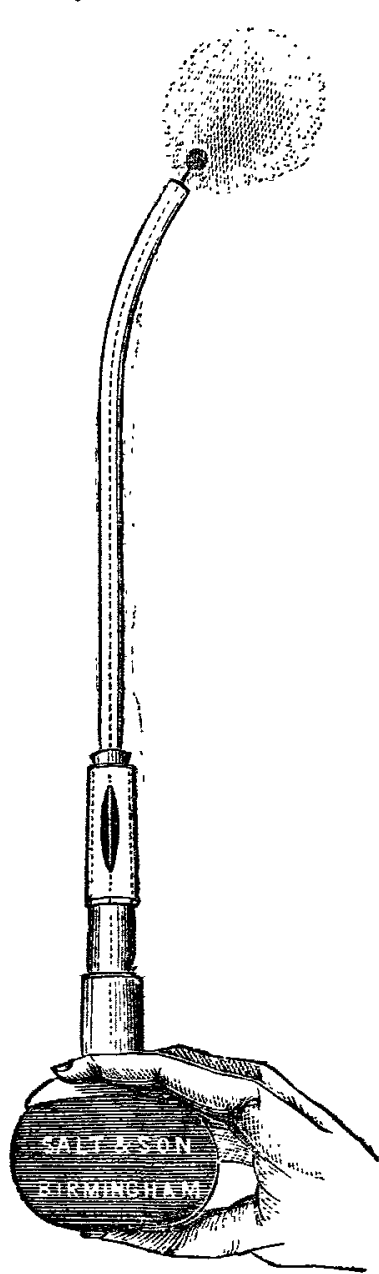
proved its thorough efficiency in every respect, I have had an en. graving of the instrument made, which I here introduce, together with a description of the mode of using the instrument.

The instrument is made of the same length and shape as Simpson's uterine sound, and after the model of the "alum puff" used for insufflating the larynx; but instead of having an open end, which would render it liable to be plugged with mucus during its introduction into the uterus, and which would prevent the escape of the powder, the instrument here depicted is provided with a movable bulbous head, which closes the end of the tube. The pressure of the thumb on the rubber ball opens the end of the tube and ejects the powder at the same time, as shown by the engraving. When the pressure of the thumb is removed from the ball, an internal spiral spring retracts the bulbous head, and thus facilitates the withdrawal of the instrument.

The powder is placed in the aperture seen at the lower end of the tube, near to the rubber ball, and is secured by means of a sliding ferule not shown in the engraving.

Messrs. Salt and Sons, Birmingham, surgical instrument manufacturers, have been very successful in producing a neat and efficient instrument. Birmingham,

\section{9. attirtor}

\section{H O S I TAL PRACTICE, BRITISH AND FOREIGN.}

Nulla autem est alia pro certo noscendi via, nisi quamplurimas et morborum et dissectionum historias, tum aliorum, tum proprias collectas habere, inter se comparare.-MokgagN De Sed.et Caus. Morb., lib.iv. Proœmium.

\section{ST. BARTHOLOMEW'S HOSPITAL.}

\section{ACUTE PLEURISY WITH EFFUSION ; PARACENTESIS} THORACIS ; RECOVERY.

(Under the care of Dr. HARRIs.)

THE treatment of acute pleurisy with effusion as illustrated in the following case, although largely adopted by continental physicians, and more particularly by Küssmaul, Bartels, and Ziemssen, has, as yet, been practised by very few in England. Much may be said for and against it; but it would appear that the weight of evidence is in its favour, especially in cases where there are no signs of com. mencing absorption of the fluid by the natural process. It is certain that the longer the lung remains compressed, the chances of re-expansion are diminished. Not only does the lymph on the pleura become firmer, but the alveoli of the lung are also liable to become agglutinated and thus destroyed. It is also well known that in some cases where there has previously been no indication of the commencement of the absorption of the fluid, the removal of a small quantity will start the process, which may then go on with even more than ordinary rapidity. 'Clinical experience has also shown that the evil effects of the admission of air into the pleural sac bave been greatly exaggerated. We must again insist on the value of Woillez's cyrtometer for estimating the degree of unilateral enlargment of the chest, for by its aid we acquire a knowledge of the size and shape of an ideal section of the two halves of the thorax.

For the following notes we are indebted to Dr. de Havilland Hall, house-physician.

Daniel D-, aged twenty, a butcher, was admitted into John ward on August 19th, 1872, when the following notes were taken:- $\mathrm{He}$ is a well-nourished man, lies on his left side, and has pain in that side on breathing. Skin moist; temperature $101^{\circ}$; pulse 108, regular; specific gravity of urine 1038, no albumen, no sugar; respiration 30 . There is absolute dulness over left chest, even above the clavicle, transgressing the median line; entire loss of vocal fremitus and resonance; only very distant breathing, probably conducted from the other side, to be heard. Bulging of the left side very marked posteriorly. On the right side is puerile breathing; good resonance. The heart's apex is to be felt beating in epigastrium; sounds heard feebly in the normal position of apex, and heard loudest on right side about the level of the fourth intercostal space; sounds clear. Patient states that he has always enjoyed good health. The illness began about three weeks ago with pain in the abdomen and left side. About a fortnight ago he had "cold shivers," but he kept at work till the 17th inst. Has not had much cough. Ordered milk diet with beef-tea, and five grains of iodide of potassium every four hours. Tincture of iodine to be painted over the affected side.

Aug. 21st.-Pulse 100 ; respiration 32 ; temperature $101.1^{\circ}$. Had a restless night; bowels acted very freely.

22nd.-Pulse 112 ; temperature $100.8^{\circ}$. No return of resonance; face becoming slightly dusky. Paracentesis thoracis performed, and seventy ounces of straw-coloured serum let out.

23rd.-Pulse 100. Passed a good night. Dulness as absolute as before paracentesis, and transgressing the median line, though after the tapping there was resonance over the sternum. On taking a measurement of the chest with a cyrtometer, the area of both sides is found to be diminished, especially the left; temperature $100 \cdot 2^{\circ}$.

31st.-For the past eight days he has remained in much the same condition; temperature varying from $99 \cdot 4^{\circ}$ to $101 \cdot 2^{\circ}$, and the pulse from 92 to 108 . To-day his temperature is $102^{\circ}$, and pulse 96 . Absolute dulness over the left 